\title{
letter
}

\section{Modulation of P2X4 pore closure by magnesium, potassium, and ATP}

${ }_{4}$ Kalyan Immadisetty ${ }^{1}$, Josh Alenciks ${ }^{2}$, and Peter Kekenes-Huskey ${ }^{1, *}$

${ }_{5}^{1}$ Stritch School of Medicine, Maywood IL 60153

${ }_{6}^{2}$ University of Kentucky, Lexington KY 40506

7 "Correspondence: pkekeneshuskey@luc.edu

${ }_{8}$ ABSTRACT The P2X4 receptor plays a prominent role in cellular responses to extracellular ATP. Through classical 9 all-atom molecular dynamics (MD) simulations totaling $24 \mu \mathrm{s}$ we have investigated how metal-complexed ATP stabilizes 10 the channel's open state and prevents its closing. We have identified two metal-binding sites, magnesium $\left(\mathrm{Mg}^{2+}\right)$ and 11 potassium $\left(\mathrm{K}^{+}\right)$, one at the intersection of the three subunits in the ectodomain (MBS1) and the second one near the ATP 12 binding site (MBS2), similar to those characterized in Gulf coast P2X. Our data indicate that when $\mathrm{Mg}^{2+}$ and $\mathrm{K}^{+}$ions are ${ }_{13}$ complexed with ATP, the channel is locked into an open state. Interestingly, irrespective of the number of bound ATP 14 molecules, $\mathrm{Mg}^{2+}$ ions bound to the MBS2 resisted collapsing of the open state protein to a closed state by stabilizing the ${ }_{15}$ ATP-protein interactions. However, when $\mathrm{Mg}^{2+}$ in the MBS2 was replaced with $\mathrm{K}^{+}$ions, as might be expected when in ${ }_{16}$ equilibrium with an extracellular solution, the interactions between the subunits were weakened and we found evidence ${ }_{17}$ of pore collapse. This collapse was apparent when fewer than two ATP were bound to MBS2 in the presence of $\mathrm{K}^{+}$. 18 Therefore, the different capacities of common cations to stabilize the channel may underlie a mechanism governing P2X4 ${ }_{19}$ channel gating in physiological systems. This study provides structural insights into the differential modulation of ATP ${ }_{20}$ activation of $\mathrm{P} 2 \mathrm{X} 4$ by $\mathrm{Mg}^{2+}$ and $\mathrm{K}^{+}$. 


\section{${ }_{21} 1$ INTRODUCTION}

${ }_{22}$ Purinergic $(\mathrm{P} 2 \mathrm{X})$ receptors are ligand-gated cation channels that localize to the plasma and intracellular vesicle ${ }_{23}$ membranes (1). P2X4 receptors are expressed in almost all mammalian tissues (2). P2X4 receptors are implicated 24 in regulating cardiac function, ATP-mediated cell death, synaptic strengthening, activation of the inflammasome in ${ }_{25}$ response to injury, multiple sclerosis (3-7), and neuropathic pain mediated by microglia (8-11). P2X4 is activated ${ }_{26}$ by adenosine triphosphate (ATP) $(3,12-14)$, during which the channel opens and allows the rapid flow of ions such ${ }_{27}$ as calcium $\left(\mathrm{Ca}^{2+}\right), \mathrm{Mg}^{2+}$, sodium $\left(\mathrm{Na}^{+}\right)$, and $\mathrm{K}^{+}(14)$ between cellular compartments. Although the P2X4 receptor ${ }_{28}$ exhibits low $\mathrm{Ca}^{2+}$ permeability, it is often associated with triggering $\mathrm{Ca}^{2+}$-sensitive intracellular processes (14-16).

${ }_{29} \mathrm{P} 2 \mathrm{X} 4$ is a homotrimer $(17,18)$, with each subunit consisting of a transmembrane domain (TMD) and an extracellular зо ectodomain (Fig. S1). Each TMD contains two TM helices (TM1 and TM2). The TM2 of each subunit together forms ${ }_{31}$ the TM pore that controls the gating of the channel $(17,18)$. P2X receptors are capable of binding up to three ATP 32 molecules (19). Each ATP binds in an orthosteric binding site (Fig. S1) between the two neighboring subunits and зз facilitates a conformational transition from a closed (inactive) to an open (active) state $(17,18)$. Although mechanisms ${ }_{34}$ of P2X4 function are increasingly understood, several structural (role of intracellular fragments and pore dilation) and ${ }_{35}$ functional aspects (activation mechanism, allosteric modulation by agonists such as ivermectin, the number of ATP ${ }_{36}$ needed to activate the channel, desensitization, and the role of metal cations in modulating the ATP-mediated activation ${ }_{37}$ of the channel) of P2X4 channels are still elusive (20,21). Knowledge about these processes is essential to understand ${ }_{38}$ how $\mathrm{P} 2 \mathrm{X} 4$ function drives cellular responses. A pressing limitation is the lack of human resolution P2X4 structures to 39 provide structural insights into its mechanisms. However, zebrafish P2X4 (zfP2X4) have been crystallized in several 40 functionally important conformations $(17,22)$. zfP2X4 shares $\sim 59 \%$ sequence identity with human P2X4 (20) and has ${ }_{41}$ been shown to form functional homomeric channels with properties comparable to mammalian orthologs (23). Hence, $42 \mathrm{zfP} 2 \mathrm{X} 4$ structures are reasonable surrogates for the modeling of human variants of this channel (20, 23).

${ }_{43}$ Ions play a critical role in the normal functioning of many proteins (24-28); it is, therefore, no surprise that divalent ${ }_{44}$ cations including zinc, magnesium, copper, cadmium, silver, and mercury were reported to modulate P2X receptors. ${ }_{45}$ For instance, it was demonstrated that zinc and copper modulate rat P2X4 receptors differently, i.e., zinc potentiates, ${ }_{46}$ whereas copper inhibits ATP current $(29,30)$. Furthermore, it was demonstrated via site-directed mutagenesis the role of 47 residue C132 in zinc potentiation (31), and residues D138 and H140 in copper inhibition in rat P2X4 receptors (31, 32). ${ }_{48}$ Similarly, it was reported that cadmium facilitates, whereas mercury inhibits ATP mediated currents in rat P2X4 49 receptors (33). Intriguingly, it was hypothesized that there are at least three metal-binding sites in P2X channels (33). ${ }_{50}$ Kasuya et al. reported an X-ray structure of Gulf Coast P2X receptor complexed with ATP and zinc (34), for which 51 identified two metal-binding sites: MBS1 and MBS2. The MBS1 is located at the intersection of three isomers in the ${ }_{52}$ ectodomain, whereas the MBS2 is located near the ATP binding site between the two isomers. Zinc and magnesium 53 bind to MBS1 and MBS2, respectively, and potentiates ATP current. Li et al. identified magnesium binding to MBS2 ${ }_{54}$ near the ATP binding domain in human P2X3 that strengthened ATP-protein interactions, which delay ATP unbinding ${ }_{55}$ and channel recovery from desensitization (35). Li et al. also proposed two different binding modes for magnesium, each ${ }_{56}$ in the presence and absence of ATP (35). It has been reported that cations binding to MBS2 in different P2X receptors ${ }_{57}$ have diversified roles (34-36). In Gulf Coast P2X, it was demonstrated that zinc bound to MBS1 potentiates ATP 58 mediated currents, but not when bound to MBS2 (34). Riedel et al. reported that $\mathrm{K}^{+}$and $\mathrm{Na}^{+}$modulate human P2X7 59 receptor-operated single channel currents (37). The same study also reported a binding site for $\mathrm{Na}^{+}$on the extracellular 60 side.

61 Despite the known dependencies of P2X4 function on metal cation binding, the structural mechanisms by which 62 common ions like $\mathrm{Mg}^{2+}$ and $\mathrm{K}^{+}$impact the channel function are less understood. All-atom molecular dynamics (MD) ${ }_{63}$ simulations have been used to investigate aspects of $\mathrm{P} 2 \mathrm{X} 4$ function, and generally encompass short nanosecond level ${ }_{64}$ unbiased MD simulations or enhanced sampling MD simulations to probe P2X4 activation (38-45). To our knowledge, ${ }_{65}$ MD studies reported thus far have not examined how cations modulate ATP activation of P2X4, which is important for ${ }_{66}$ understanding channel function in mixed electrolyte solutions typical of cellular environments. Hence, we investigated ${ }_{67}$ the metal-binding sites, as well as the differential role of metal cations such as $\mathrm{Mg}^{2+}$ and $\mathrm{K}^{+}$, in modulating the ${ }_{68}$ ATP mediated activation of P2X4 via microsecond-length MD simulations (totaling $24 \mu s$ ). We have identified two 
69 metal-binding sites MBS1 and MBS2, similar to gulf coast P2X (34), for which $\mathrm{Mg}^{2+}$ and $\mathrm{K}^{+}$binding to the latter have

70 different capacities to facilitate $\mathrm{P} 2 \mathrm{X} 4$ pore closing.

\section{${ }_{71} 2$ RESULTS AND DISCUSSION}

\section{1 $\mathrm{Mg}^{2+}$ ions modulating ATP activation of P2X4}

${ }_{73}$ Three inter-subunit metal and ATP binding sites were identified in Gulf Coast P2X (34) and human P2X3 (35), which 74 have been coined as the metal binding site 2 (MBS2) sites. To understand the role of $\mathrm{Mg}^{2+}$ binding at the MBS2 site in 75 P2X4, we simulated five P2X4 open state structures. Three of the states have one equivalent of $\mathrm{Mg}^{2+}$ bound for each 76 ATP: 3 ATP- $3 \mathrm{Mg}^{2+}$ (three ATP and three $\mathrm{Mg}^{2+}$ bound), 2 ATP- $2 \mathrm{Mg}^{2+}$ (two ATP and two Mg ${ }^{2+}$ bound), and 1 ATP-1 $77 \mathrm{Mg}^{2+}$ (one ATP and one $\mathrm{Mg}^{2+}$ bound). We also considered two cases with excess bound $\mathrm{Mg}^{2+}: 1 \mathrm{ATP}^{2} 3 \mathrm{Mg}{ }^{2+}$ (one 78 ATP and three $\mathrm{Mg}^{2+}$ bound) and 2 ATP-3 $\mathrm{Mg}^{2+}$ (two ATP and three $\mathrm{Mg}^{2+}$ bound). (Fig. 1, Fig. S2). The latter were 79 modeled in order to determine whether ATP was necessary to facilitate $\mathrm{Mg}^{2+}$ binding between the interfaced channel ${ }_{80}$ subunits. Three replicas of each system were simulated for $1 \mu$ s each. All five systems stabilized after $400 \mathrm{~ns}$ as reflected ${ }_{81}$ in the protein backbone root mean squared deviations (RMSD) (Fig. S3A) that approached less than $4 \AA$ in all cases 82 (Fig. S3). We first investigated the stability of $\mathrm{Mg}^{2+}$ ions in the MBS2 sites. Our data suggest that $\mathrm{Mg}^{2+}$ were not stable ${ }_{83}$ in the absence of ATP in the neighboring nucleotide binding site. Specifically, for the 1 ATP-3 $\mathrm{Mg}^{2+}$ and $2 \mathrm{ATP}^{2} 3 \mathrm{Mg}^{2+}$ ${ }_{84}$ systems, two and one $\mathrm{Mg}^{2+}$ that were bound to the vacant MBS2 sites left the sites spontaneously (Fig. S4).

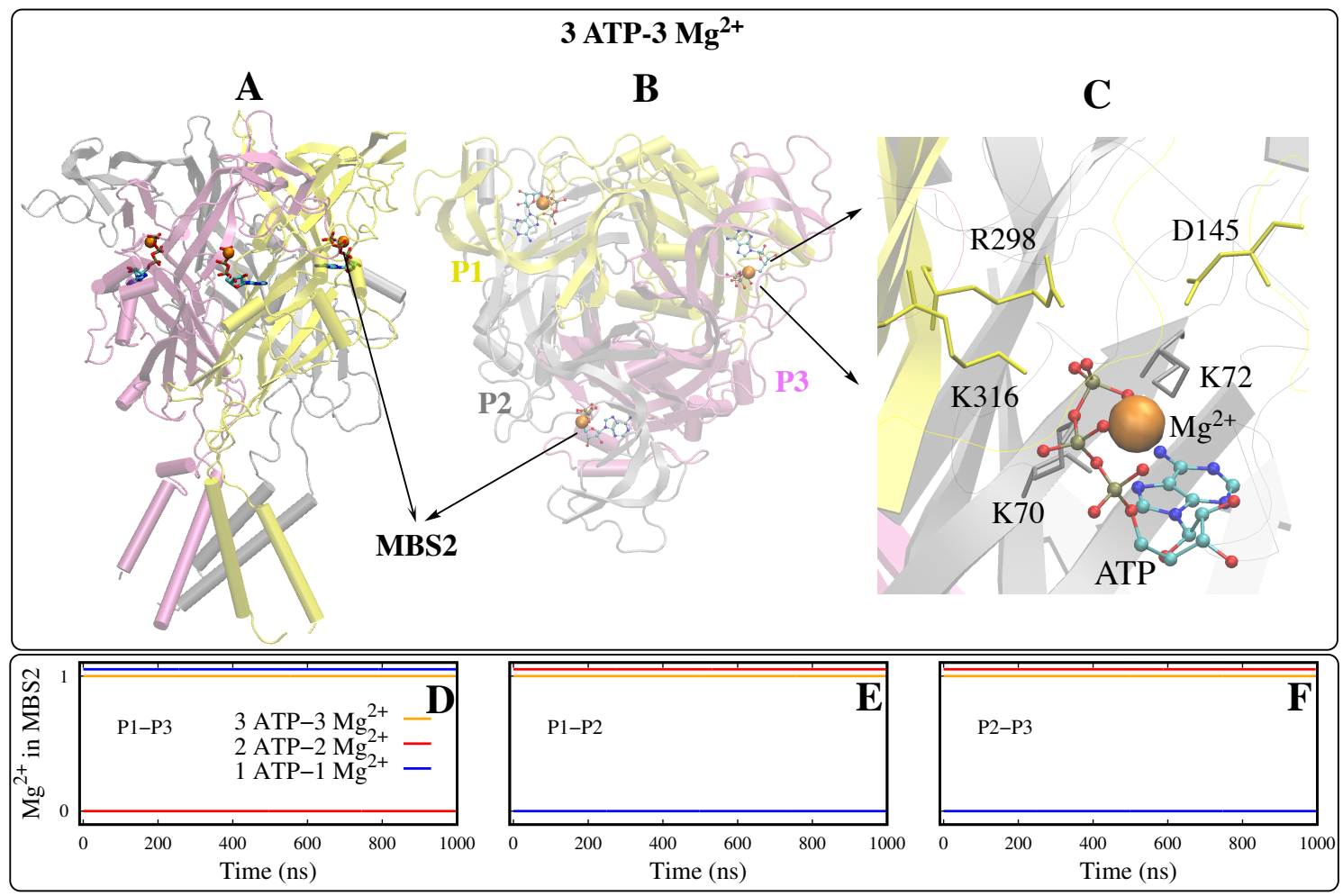

Figure 1: The open state P2X4 structure bound to three ATP and three $\mathrm{Mg}^{2+}\left(3 \mathrm{ATP}-3 \mathrm{Mg}^{2+}\right) . \mathrm{Mg}^{2+}$ were docked into MBS2, which is located near the ATP binding site. P1, P2, and P3 isomers are colored yellow, grey, and magenta, respectively. Shown in panels A and B are the side and top views of the channel. The close-up of MBS2 is shown in panel C. Residues within $6 \AA$ of $\mathrm{Mg}^{2+}$ are shown. Residues are colored to match the respective isomer. $\mathrm{Mg}^{2+}$ are shown as orange spheres and ATP is represented as a ball and stick model. (D-F) Time series of presence of $\mathrm{Mg}^{2+}$ in the the three MBS2 sites. 0 and 1 on Y-axis represent the absence and presence of $\mathrm{Mg}^{2+}$, respectively, in the MBS2 sites.

85 Activation of the channel by ATP opens the TM pore; pore opening is frequently measured by the positions of the ${ }_{86}$ L351 residue on each subunit, which borders the narrowest part of the TM pore (Fig. 2A) (19). Therefore, we report the ${ }_{87}$ radius of gyration $\left(\mathrm{R}_{g}\right)$ of the residues L351 from each subunit (Fig. 2A) to assess the extent of the pore opening. The ${ }_{88} \mathrm{R}_{g}$ values for all four systems (except for $1 \mathrm{ATP}-3 \mathrm{Mg}^{2+}$ ) were distributed between 4.5 and $6 \AA$, with an average of $\approx 5$ ${ }_{89} \AA$ that is comparable to the open state $\mathrm{zfP} 2 \mathrm{X} 4$ crystal structure $(\approx 5.3 \AA)$. We did not observe significant differences ${ }_{90}$ in the distribution of $\mathrm{R}_{g}$ values between the systems simulated (Fig. $2 \mathrm{~B}$ and Fig. S5). Hence, these data indicate that ${ }_{91}$ irrespective of the number of ATP and $\mathrm{Mg}^{2+}$ binding, the channel has not collapsed back to the closed state. 

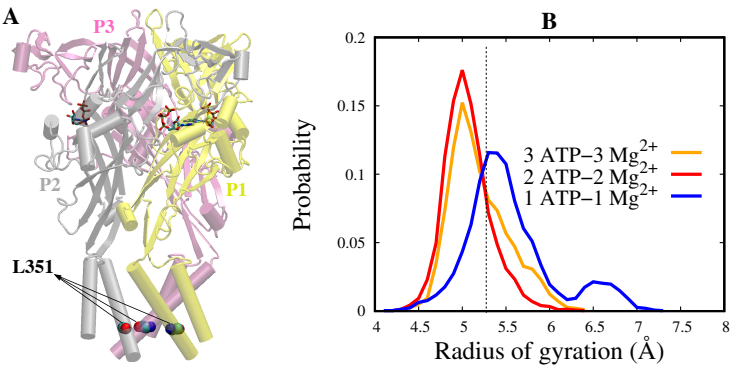

Figure 2: Probability density of the radius of gyration $\left(\mathrm{R}_{g}\right)$. L351 of the three isomers were used for the calculation of $\mathrm{R}_{g}$ (A). Only $\mathrm{C}_{\alpha}$ atoms of $\mathrm{L} 351$ were considered. Probability densities of $\mathrm{Mg}^{2+}$ bound systems are shown in panel B. The dotted vertical line represents the $\mathrm{R}_{g}$ of the open state $\mathrm{zfP} 2 \mathrm{X} 4$ crystal structure.

\section{${ }_{92} 2.2 \mathrm{~K}^{+}$ions modulating ATP activation of the P2X4}
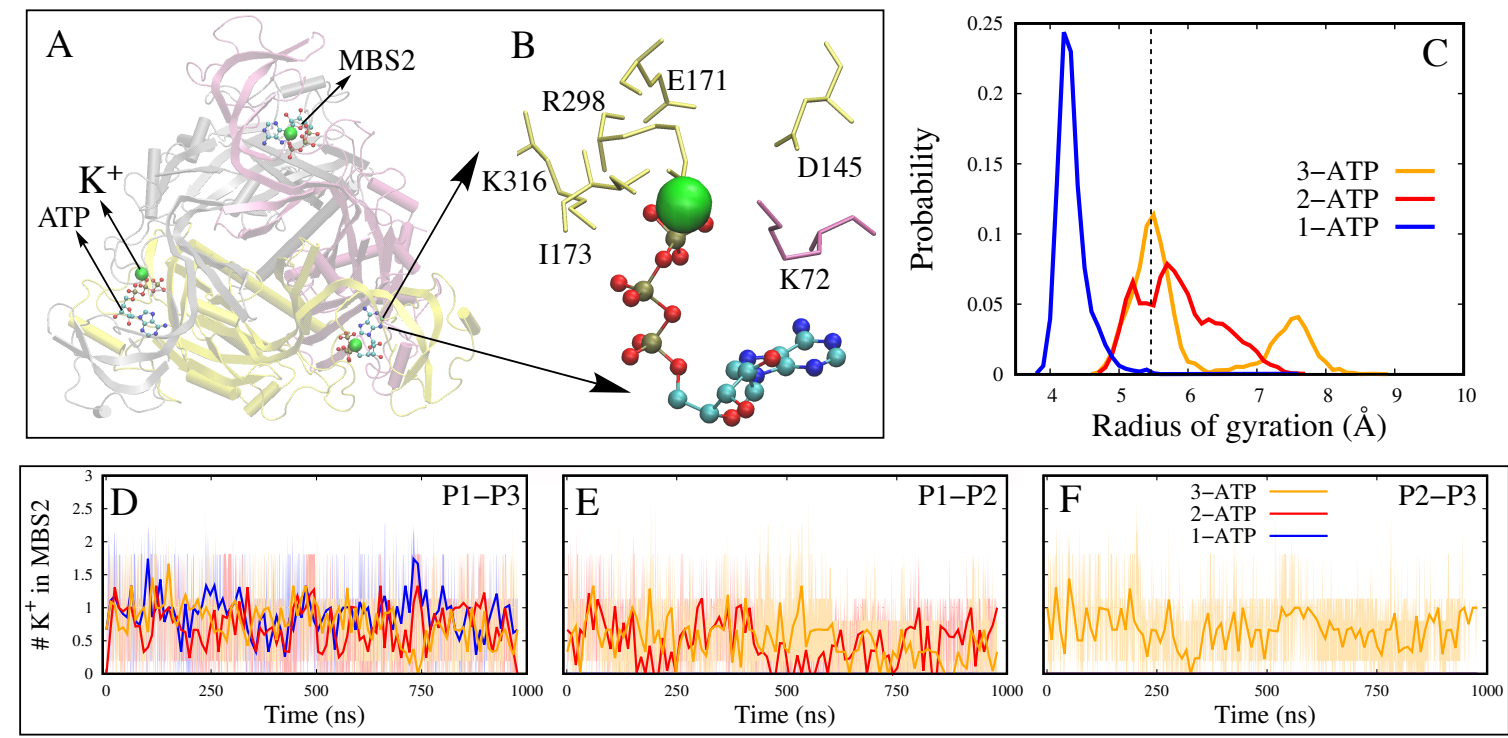

Figure 3: $\mathrm{K}^{+}$binding in MBS2 site in P2X4. (A) $\mathrm{K}^{+}$ions within 5 A of ATP and protein in MBS2 are shown. (B) MBS2 between P1 and P3 is shown in close-up. Green spheres are $\mathrm{K}^{+}$ions. ATP is shown as a ball and stick model. Residues within $5 \AA$ of ions are shown. Residues are colored to match the respective isomers. (C) Probability density plots of the radius of gyration $\left(\mathrm{R}_{g}\right)$ values of residue $\mathrm{L} 351$. The dotted vertical line represents the $\mathrm{R}_{g}$ of the open state zfP2X4 crystal structure. (D-F) The average number of $\mathrm{K}^{+}$ions binding to MBS2s between the isomers P1,P3 (F), P1,P2 (G), and P2,P3 (H). Ions within $5 \AA$ of both ATP and protein are estimated. 1-, 2-, and 3-ATP systems are colored blue, red, and orange, respectively. Average and standard of the three MD trials are shown.

The data in Section 2.1 suggest that the channel is stabilized in an open state irrespective of the number of bound ${ }_{94}$ ATP. Therefore, we speculated $\mathrm{Mg}^{2+}$ may exchange with monovalent ions like $\mathrm{Na}^{+}$and $\mathrm{K}^{+}$, given that the concentration ${ }_{95} \mathrm{Sf}^{2+}$ is roughly 100 -fold lower than the $154 \mathrm{mM}$ intracellular concentration of $\mathrm{K}^{+}$and extracellular concentration of ${ }_{96} \mathrm{Na}^{+}$, respectively. To investigate this hypothesis, we simulated three P2X4 open state receptors, each docked with one, ${ }_{97}$ two, and three ATP molecules, respectively (Fig. S9) in the absence of $\mathrm{Mg}^{2+}$. During the simulation, solvated $\mathrm{K}^{+}$ions 98 infiltrated the MBS2 region and interacted with the ATP (Fig. 3A,B), as at least one $\mathrm{K}^{+}$ion was bound in each MBS2 99 (Fig. 3D-F). Importantly, we found that MBS2 sites lacking ATP did not accommodate $\mathrm{K}^{+}$ion, which was consistent 100 with our findings using $\mathrm{Mg}^{2+}$.

101 To assess the impact of the number of ATP molecules and the binding of $\mathrm{K}^{+}$ions on the opening/closing of the 102 channel, we measured the pore radius by estimating the $\mathrm{R}_{g}$ of the TM pore residue L351 as explained in Sect. 2.1. While 103 the 2- \& 3-ATP systems resisted the pore collapse as was observed for the $\mathrm{Mg}^{2+}$-bound systems, the TM pore of the 104 1-ATP system collapsed within the first $5 \mathrm{~ns}$ of these simulations. The average pore radius for the 1-ATP system was ${ }_{105} \approx 4.2 \AA$ (Fig. 2C), whereas for the 2- and 3-ATP systems it was $\approx 5.5 \AA$ (Fig. 2C), except for one 3-ATP trail (Fig. 2C). ${ }_{106}$ These data suggest that the substitution of $\mathrm{K}^{+}$for $\mathrm{Mg}^{2+}$ weakens the coupling between channel subunits, such that the ${ }_{107}$ channel collapses when fewer than two ATP are bound. We speculate that the 1-ATP system conformation obtained in ${ }_{108}$ our simulation may resemble a desensitized state in which ATP is still bound but the TM pore is closed; full deactivation 109 would requite ATP to unbind completely $(35,46)$. 


\section{${ }_{110}$ 2.3 Mechanisms of $\mathrm{K}^{+}$vs. $\mathrm{Mg}^{2+}$ channel closing}

${ }_{111}$ To investigate the potential mechanisms coupling the MBS2 sites to channel opening, we performed dynamic cross112 correlation analysis (DCCA) to identify the correlations between dynamic regions of the receptor. Correlation coefficient ${ }_{113}$ matrices were computed for each system to identify regions of strong positive (red) or negative (cyan) correlations ${ }_{114}$ (Fig. S7). In general, the matrices were similar among the $\mathrm{Mg}^{2+}$ bound systems, which suggests that channel dynamics 115 are comparable irrespective of the number of bound $\mathrm{Mg}^{2+}$-ATP equivalents. However, to better highlight the similarities, 116 we provide a correlation of each subunit residue with respect to several functionally important residues: K70, D145, and ${ }_{117}$ L351 (Fig. 4). Residue K70 contributes to the MBS2 within a given subunit, whereas D145 lines the MBS2 site of 118 an adjacent subunit. In Fig. 4A we show that K70 of one subunit is anticorrelated with the D145 of the same subinit ${ }_{119}$ (Fig. 4B, D), indicating that these two residues are pulled in opposite directions. We additionally observed that the TM ${ }_{120}$ pore residue L351 is negatively correlated with the remainder of the subunit (e.g., the MBS2 residues) (Fig. 4B, D).

${ }_{121}$ Given our observation that the channel partially closes when one equivalent of ATP is bound in the absence of $\mathrm{Mg}^{2+}$, 122 we hypothesized that replacing $\mathrm{Mg}^{2+}$ with $\mathrm{K}^{+}$in MBS2 would weaken the dynamic coupling between the MBS2 and ${ }_{123}$ the pore regions. Indeed, the DCCA data for the $2-$ and 3-ATP/K ${ }^{+}$bound systems (Fig. S7 and Fig. S12) were similar to ${ }_{124}$ the $\mathrm{Mg}^{2+}$ bound systems (Fig. 4 and Fig. S7). In contrast, the DCCA data were significantly different in the presence of ${ }_{125}$ a single bound ATP compared to the 3- and 2-ATP systems, respectively (Fig. S7 and Fig. S12). As an example, the ${ }_{126}$ correlation of the MBS2 site residue D145 with the L351 of a subunit is $\approx 7 \%$ in the 3 ATP- $3 \mathrm{~K}^{+}$system, whereas their ${ }_{127}$ motions were strongly negatively correlated $(\approx-50 \%)$ between the same residues in the same subunit in the 1 ATP-1 ${ }_{128} \mathrm{~K}^{+}$system (Fig. S12). Overall, our $\mathrm{K}^{+}$bound simulations suggest that the ATP- $\mathrm{K}^{+}$bound complex weakly stabilizes the 129 subunit interfaces, such that losing two $\mathrm{K}^{+}$is sufficient for the system to collapse back to a closed state.
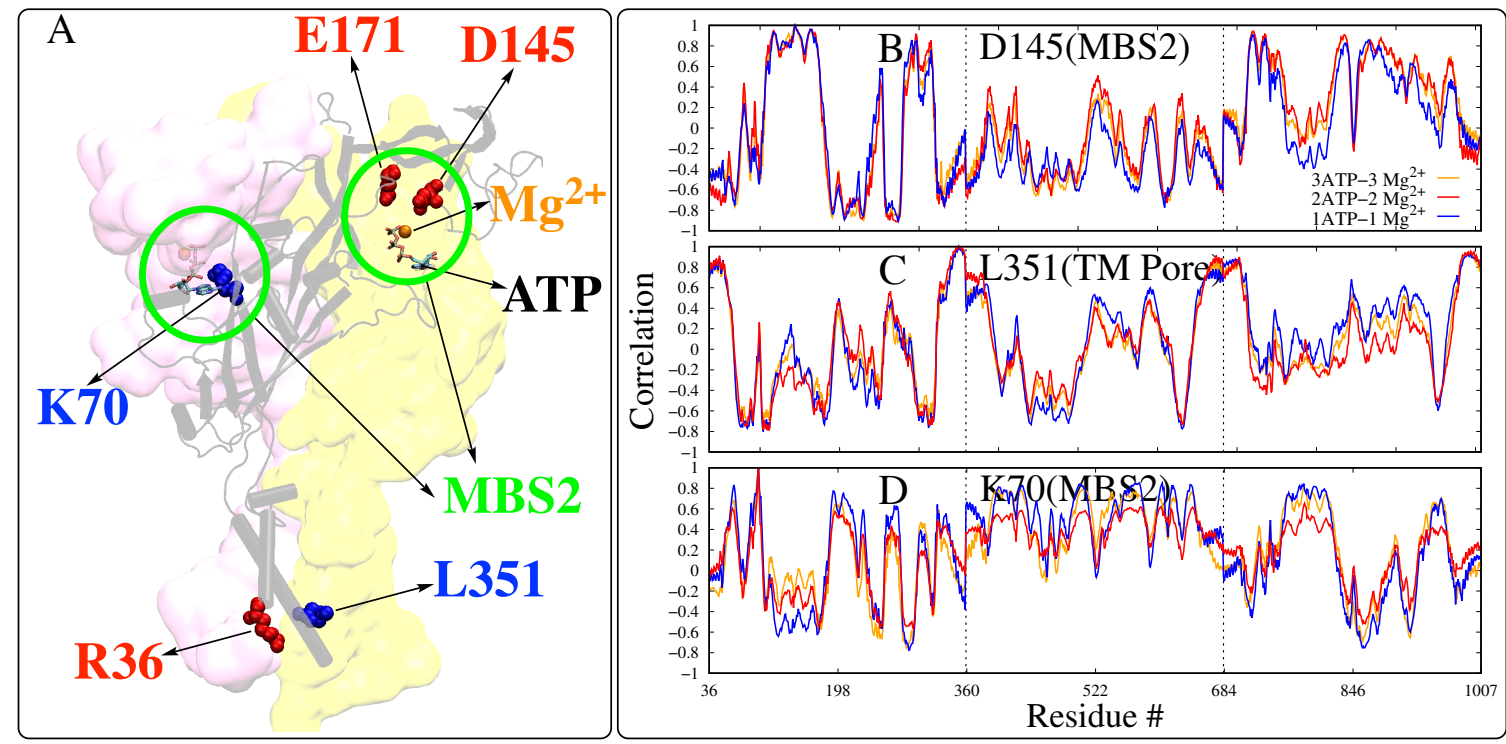

Figure 4: Inter-residue correlations in $\mathrm{Mg}^{2+}$ bound systems. (A) Residues of interest that belong to the isomer (colored grey and represented as a cartoon) are shown. The blue-colored residues are positively correlated with each other and the red and blue residues are anticorrelated. ATP is shown as sticks and $\mathrm{Mg}^{2+}$ bound in the MBS2 site is shown as orange spheres. The two MBS2 sites are circled in green. (B-C) Correlation plots of a select few residues of interest are shown on right. The dotted lines separate the three subunits. $-1,0$, and 1 on the $y$-axis refers to anticorrelation, no correlation, and positive correlation, respectively.

\section{${ }_{130} 2.4 \mathrm{Mg}^{2+}$ vs. $\mathrm{K}^{+}$coordination of ATP-protein interactions}

${ }_{131}$ To determine the basis of the different correlation patterns reported in Section 2.3, we examined how the protein ${ }_{132}$ coordinates the ATP/metal complexes at the MBS2 sites. It is evident in all ATP-bound cases that the adenine base of ${ }_{133}$ ATP directly interacts with one subunit (i.e., the subunit colored yellow in Fig. 5A, B), whereas its phosphate backbone ${ }_{134}$ interacts with residues D145 and E171 of a neighboring subunit (i.e., the subunit colored grey in Fig. 5A, B) via metal ${ }_{135}$ cations. In other words, the bound ATP bridges two interfaced subunits. Interestingly, waters appear to mediate the ${ }_{136}$ interactions between metals and residues D145 and E171. Analogous sites are implicated in coordinating the binding of ${ }_{137}$ metal ions in the MBS2 site in Gulf coast P2X (34) and hP2X3 (35). To quantify this coordination, we assessed the 

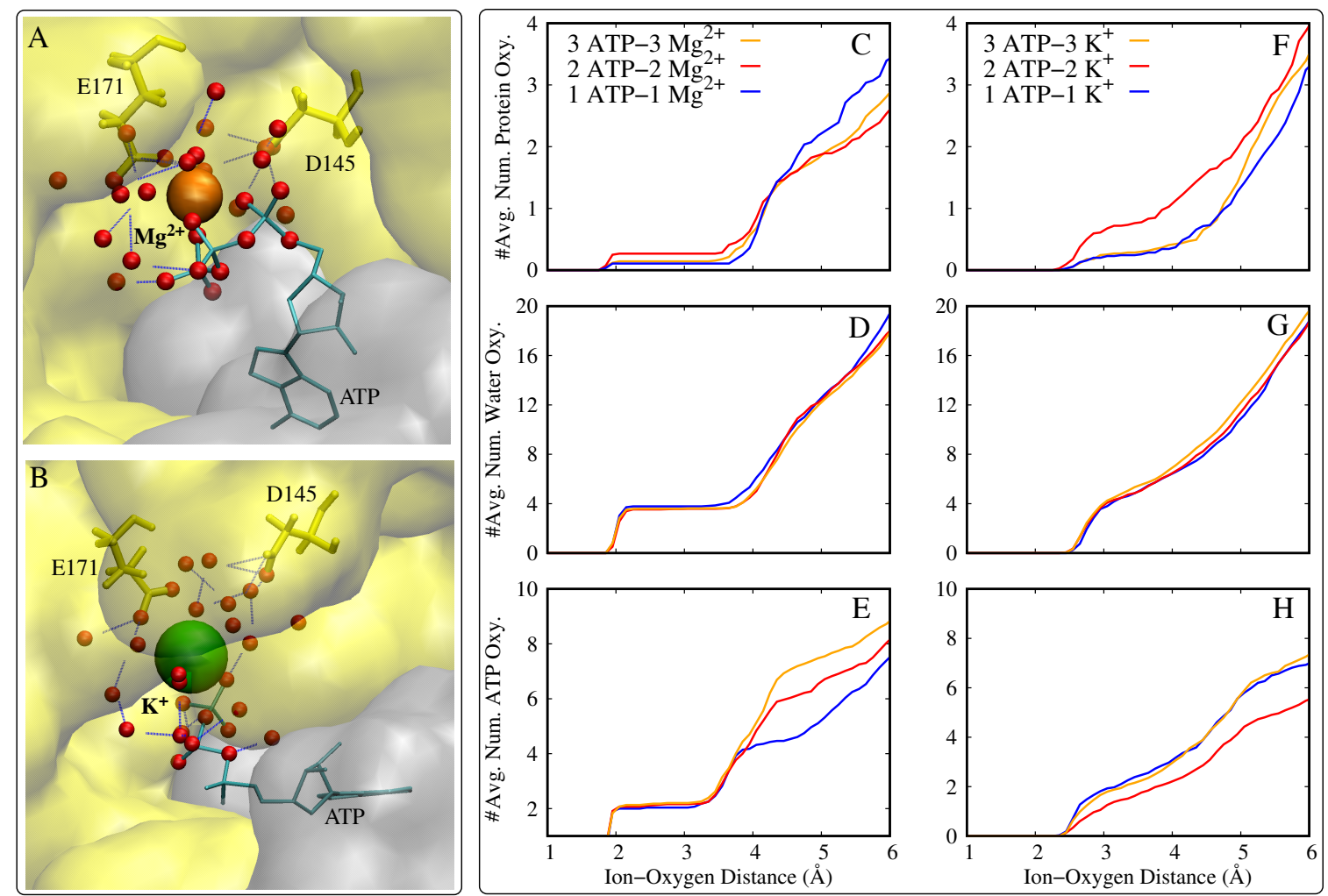

Figure 5: Metal cations coordinating the ATP-protein interactions in the MBS2 sites. (A) MBS2 3 ATP- $3 \mathrm{Mg}^{2+}$ system; (B) MBS2 in 3 ATP- $\mathrm{K}^{+}$bound system. The two neighboring subunits are shown in yellow and grey and in surface representation. Oxygen atoms (belonging to water, protein, and ATP) within $6 \AA$ of the ions are shown as red spheres. Hydrogen bonds are shown as blue broken lines. $\mathrm{Mg}^{2+}$ and $\mathrm{K}^{+}$are shown as orange and green spheres, respectively. ATP is shown as cyan and in stick representation. Residues D145 and E171 are shown as yellow sticks. ATP connects the subunit colored grey to the one in yellow (i.e., to residues D145 and E171) via metal ions and water molecules. $(\mathrm{C}-\mathrm{H})$ Oxygen coordination around $\mathrm{Mg}^{2+}(\mathrm{C}-\mathrm{E})$ and $\mathrm{K}^{+}(\mathrm{F}-\mathrm{H})$ ions binding in the MBS2. Integrated amino acid, water, and ATP oxygen distribution are shown separately for each ion. The average number of oxygens around a single $\mathrm{Mg}^{2+}$ or $\mathrm{K}^{+}$ion is shown. All three MD trials of each system were combined for these calculations.

${ }_{138}$ distribution of oxygens contributed by the protein and associated waters about $\mathrm{Mg}^{2+}$ and $\mathrm{K}^{+}$cations bound at the MBS2 139 site (Fig. 5). The radius of the first oxygen shell near $\mathrm{Mg}^{2+}$ is at $\approx 2 \AA$ and comprises four water oxygens, with two 140 oxygens from the ATP phosphate and minor $(<1)$ contributions from the receptor. Visual inspection of the binding site ${ }_{141}$ indicates the bound waters bridge $\mathrm{Mg}^{2+}$ with residues D145 and E171. We report similar oxygen distributions for $\mathrm{K}^{+}$ 142 as well, albeit the radius of the first oxygen shell was considerably larger $(\approx 3 \AA)$. Although both ions seem to utilize ${ }_{143}$ similar binding partners, bound $\mathrm{Mg}^{2+}$ may afford tighter coordination at the MBS2 site, which could serve to effectively ${ }_{144}$ lock adjacent channel subunits into an open configuration. $\mathrm{K}^{+}$ions, in contrast, more weakly interface the subunits, ${ }_{145}$ which potentially permit channel closure. Hence, the bound waters might contribute to a water-mediated allosteric 146 network stabilizing the P2X4 channel open state, similar to water-mediated hydrogen-bond networks shown to govern ${ }_{147}$ the conformational dynamics of other proteins such as aurora kinase A (47).

\section{${ }_{148} 3$ CONCLUSION}

149 In this report, we studied the modulation of ATP activation of P2X4 by metal cations via all-atom MD simulations. We 150 identified two metal-binding sites similar to other P2X receptors, such as Gulf coast P2X. The first metal-binding site ${ }_{151}$ (MBS1) was found at the intersection of three isomers in the upper part of the vestibule and the second metal-binding ${ }_{152}$ site (MBS2) resided near the ATP binding site. We investigated how the binding of $\mathrm{Mg}^{2+}$ versus $\mathrm{K}^{+}$at $\mathrm{MBS} 2$ modulates ${ }_{153}$ ATP mediated channel closing. Our data suggest $\mathrm{Mg}^{2+}$ ions stabilize the coupling between channel subunits and ${ }_{154}$ thereby prevent the collapse of the open state to a closed state, irrespective of the number of ATP molecules binding ${ }_{155}$ to the channel. It has been reported that the ATP- $\mathrm{Mg}^{2+}$ complex delays the human P2X3 receptor's recovery from ${ }_{156}$ desensitization (35), hence bound $\mathrm{Mg}^{2+}$ in P2X4 may contribute to a long recovery from desensitization. In contrast, the ${ }_{157}$ exchange of $\mathrm{Mg}^{2+}$ with $\mathrm{K}^{+}$, which is expected when more highly concentrated $\mathrm{K}^{+}$is in thermodynamic equilibrium with ${ }_{158}$ low concentration $\mathrm{Mg}^{2+}$, permits channel closing when a single equivalent of ATP is bound. We therefore speculate 159 that weakening of the subunit coupling, e.g., via $\mathrm{Mg}^{2+}$ replacement with $\mathrm{K}^{+}$facilitates the collapse of the channel. 
${ }_{160}$ Interestingly, it was found for a related purinergic receptor, P2X7, that one ATP was sufficient to activate the channel even 161 in the absence of $\mathrm{Mg}^{2+}(48)$, which suggests that purinoreceptors may utilize different mechanisms for ion-dependent 162 regulation. Our simulations also suggest that MBS1 readily binds metal cations $\left(\mathrm{K}^{+}\right)$to bridge the interactions between ${ }_{163}$ its three subunits, but does not appear to be sensitive to the metal identity at MBS2. For this reason, they may contribute 164 to stabilization of the trimer interface. Altogether, our study provides insight into metal-mediated interactions in the ${ }_{165} \mathrm{P} 2 \mathrm{X} 4$ channel that may contribute to its channel gating properties in multi-electrolyte cellular environments.

\section{${ }_{66} 4$ METHODS}

\section{${ }_{167}$ 4.1 Molecular dynamics simulations}

${ }_{168}$ The open state crystal structure of zfP2X4 bound with three ATP molecules (PDB: 4DW1 (22)) was utilized for this study. ${ }_{169}$ Initially, the open state zfP2X4 crystal structure was obtained from the protein data bank (49) and all waters were removed. 170 Two and one ATP bound open state zfP2X4 systems were generated by removing ATP from the three ATP bound crystal 171 structure. All three systems were further processed and built for the MD simulation using the CHARMM-GUI web 172 server $(50,51)$. Namely, each system was placed in the 1-palmitoyl-2-oleoyl-sn-glycero-3-phosphocholine (POPC) ${ }_{173}$ bilayer and solvated using TIP3P water $(52) . \mathrm{K}^{+}$and chloride $\left(\mathrm{Cl}^{-}\right)$ions were added to balance the charges as 174 well as to attain a physiological concentration of $0.15 \mathrm{M}$. Each system contained one P2X4 protein, $\approx 42,425$ TIP3P 175 water molecules, $\approx 388$ POPC lipid molecules, $0.15 \mathrm{M} \mathrm{KCl}$, and 3/2/1 ATP molecules. The size of each system was $176 \approx 155 \times 160 \times 170 \AA^{3}$ and the total number of atoms in each system is $\approx 195,116$. The amber force field (ff12SB) (53) 177 was used to treat the entire system. All three systems described above were simulated (three replicas for each system) 178 with $\mathrm{Mg}^{2+}$ ions docked near the site of ATP binding as described in the references $(34,35)$. For the 2-ATP and 1-ATP 179 systems, $\mathrm{Mg}^{2+}$ was only docked to the sites that contain ATP. Additionally, 2-ATP and 1-ATP systems were generated 180 but with $\mathrm{Mg}^{2+}$ docked in all three domains irrespective of the presence of ATP molecules. Overall, five $\mathrm{Mg}^{2+} \mathrm{docked}^{2}$ ${ }_{181}$ open state zfP2X4 systems were modeled for MD simulations; a 3-ATP system with $\mathrm{Mg}^{2+}$ found at each docking site, 182 two 2-ATP systems, and two 1-ATP systems. The 2-ATP and 1-ATP had one system each with $\mathrm{Mg}^{2+}$ docked in all three 183 domains and one system each where $\mathrm{Mg}^{2+}$ only docked in the domains where ATP is present. $\mathrm{Mg}^{2+}$ was removed from 184 the input structures in order to model the $\mathrm{K}^{+}$-bound configurations; however, the $\mathrm{K}^{+}$ions were not docked into the ${ }_{185}$ MBS2 sites but rather spontaneously coordinated from the surrounding water box during the MD simulations.

186 Each system was energy minimized for 100,000 steps using a conjugate gradient algorithm (54), and further relaxed 187 in a multistep procedure (which spans for $\approx 1.5 \mathrm{~ns}$ ), wherein the lipid tails, protein side chains, and backbone were ${ }_{188}$ restrained and then released in a step-wise manner as explained elsewhere (50) in the NVT ensemble. Furthermore, 189 production simulations were conducted under periodic boundary conditions in NPT ensemble. Three replicas of each 190 system were simulated, each replica for $\sim 1 \mu s(1 \mu s \times 3$ trials $\times 3$ systems $=9 \mu s)$. AMBER16 (55) was used for 191 conducting the MD simulations. A 2 fs time step was used for the initial relaxation as well as for the follow-up production 192 simulations. The temperature was maintained at $310 \mathrm{~K}$ using a Langevin thermostat and the Nose-Hoover Langevin 193 piston method was used to maintain a 1 atm pressure $(56,57)$. The nonbonded interactions were cut-off at $12 \AA$ and the 194 particle mesh Ewald (PME) method (58) was used to treat the long-range electrostatics. Trajectories were saved every 19520 ps. The SHAKE algorithm was used to constrain the hydrogen bonds (59).

196 All simulations were conducted on a local GPU cluster and using XSEDE resources. Data analysis was conducted 197 using VMD plugins (60) and the cpptraj module of Amber (61). Five data points per each ns were used for analysis. 198 Simulation input files and generated data are available upon request. Dynamic cross-correlation maps were generated to 199 understand the correlated motions of the protein. Cpptraj (61) package of Amber was used for users to conduct this 200 analysis and only $\mathrm{C}_{\alpha}$ atoms of the protein were used to calculate the correlation coefficients. All three MD trials of each 201 system were combined and a correlation matrix was generated for the entire protein. 


\section{${ }_{202} 5$ AUTHOR CONTRIBUTIONS}

${ }_{203} \mathrm{KI}$ and JA conducted the simulations, analyzed the data, and wrote the manuscript. PKH designed the project, analyzed 204 the data, and wrote the manuscript.

\section{${ }_{205} 6$ ACKNOWLEDGMENTS}

206 Research reported in this publication was supported by the Maximizing Investigators' Research Award (MIRA) (R35) 207 from the National Institute of General Medical Sciences (NIGMS) of the National Institutes of Health (NIH) under grant ${ }_{208}$ number R35GM124977. This work used the Extreme Science and Engineering Discovery Environment (XSEDE) (62), 209 which is supported by the National Science Foundation grant number ACI-1548562.

\section{BIBLIOGRAPHY}

211 1. Kaczmarek-Hájek, K., É. Lörinczi, R. Hausmann, and A. Nicke, 2012. Molecular and functional properties of P2X receptors—recent progress and persisting challenges. Purinergic signalling 8:375-417. 1 receptors studied with an ectodomain antibody. Cell and tissue research 313:159-165. 1 myocytes: implications for a cardiac physiologic role of P2X4 receptors. The FASEB Journal 20:277-284. 1

217 4. Solini, A., E. Santini, D. Chimenti, P. Chiozzi, F. Pratesi, S. Cuccato, S. Falzoni, R. Lupi, E. Ferrannini, G. Pugliese, et al., 2007. Multiple P2X receptors are involved in the modulation of apoptosis in human mesangial cells: evidence for a role of P2X4. American Journal of Physiology-Renal Physiology 292:F1537-F1547.

220 5. Baxter, A. W., S. J. Choi, J. A. Sim, and R. A. North, 2011. Role of P2X4 receptors in synaptic strengthening in mouse CA1 hippocampal neurons. European Journal of Neuroscience 34:213-220.

222 6. Kawano, A., M. Tsukimoto, T. Noguchi, N. Hotta, H. Harada, T. Takenouchi, H. Kitani, and S. Kojima, 2012. Involvement of $\mathrm{P} 2 \mathrm{X} 4$ receptor in $\mathrm{P} 2 \mathrm{X} 7$ receptor-dependent cell death of mouse macrophages. Biochemical and biophysical research communications 419:374-380.

228 8. Ulmann, L., H. Hirbec, and F. Rassendren, 2010. P2X4 receptors mediate PGE2 release by tissue-resident macrophages and initiate inflammatory pain. The EMBO journal 29:2290-2300. 1 mice lacking purinergic P2X 4 receptors in acute and chronic pain assays. Molecular pain 5:28.

${ }_{232}$ 10. Ulmann, L., J. P. Hatcher, J. P. Hughes, S. Chaumont, P. J. Green, F. Conquet, G. N. Buell, A. J. Reeve, I. P. ${ }_{233}$ Chessell, and F. Rassendren, 2008. Up-regulation of P2X4 receptors in spinal microglia after peripheral nerve ${ }_{234} \quad$ injury mediates BDNF release and neuropathic pain. Journal of Neuroscience 28:11263-11268.

235 11. Tsuda, M., Y. Shigemoto-Mogami, S. Koizumi, A. Mizokoshi, S. Kohsaka, M. W. Salter, and K. Inoue, 2003. P2X

236 4 receptors induced in spinal microglia gate tactile allodynia after nerve injury. Nature 424:778. 1

237 12. Rothwell, S. W., P. J. Stansfeld, L. Bragg, A. Verkhratsky, and R. A. North, 2014. Direct Gating of ATP-activated Ion Channels (P2X2 Receptors) by Lipophilic Attachment at the Outer End of the Second Transmembrane Domain. Journal of Biological Chemistry 289:618-626. 1 
240 13. Khadra, A., Z. Yan, C. Coddou, M. Tomić, A. Sherman, and S. S. Stojilkovic, 2012. Gating properties of the

${ }_{241}$ P2X2a and P2X2b receptor channels: Experiments and mathematical modeling. The Journal of general physiology $139: 333-348$

243 14. North, R. A., 2002. Molecular Physiology of P2X Receptors. Physiological Reviews 82:1013-1067. 1

244 15. Shigetomi, E., and F. Kato, 2004. Action potential-independent release of glutamate by Ca2+ entry through

245 presynaptic P2X receptors elicits postsynaptic firing in the brainstem autonomic network. Journal of Neuroscience $246 \quad 24: 3125-3135$

247 16. Koshimizu, T.-a., F. Van Goor, M. Tomić, A. O.-L. Wong, A. Tanoue, G. Tsujimoto, and S. S. Stojilkovic, 2000.

${ }_{248}$ Characterization of calcium signaling by purinergic receptor-channels expressed in excitable cells. Molecular $249 \quad$ pharmacology 58:936-945. 1

250 17. Kawate, T., J. C. Michel, W. T. Birdsong, and E. Gouaux, 2009. Crystal structure of the ATP-gated P2X 4 ion $251 \quad$ channel in the closed state. Nature 460:592. 1

252 18. Hatoé, Z., D. Boda, and T. Kristoéf, 2012. Simulation of steady-state diffusion: Driving force ensured by dual ${ }_{253}$ control volumes or local equilibrium Monte Carlo. The Journal of chemical physics 137:54109. 1

254 19. Hattori, M., and E. Gouaux, 2012. Molecular mechanism of ATP binding and ion channel activation in P2X receptors. Nature 485:207. 1, 2.1

256 20. Grimes, L., and M. T. Young, 2015. Purinergic P2X receptors: structural and functional features depicted by X-ray 257 and molecular modelling studies. Current medicinal chemistry 22:783-98. 1

258 21. Wang, J., and Y. Yu, 2016. Insights into the channel gating of P2X receptors from structures, dynamics and small molecules. Acta Pharmacologica Sinica 37:44-55. 1

260 22. Hattori, M., and E. Gouaux, 2012. Molecular mechanism of ATP binding and ion channel activation in P2X

261 receptors. Nature $1,4.1$

262 23. Diaz-Hernandez, M., J. A. Cox, K. Migita, W. Haines, T. M. Egan, and M. M. Voigt, 2002. Cloning and ${ }_{263}$ characterization of two novel zebrafish $\mathrm{P} 2 \mathrm{X}$ receptor subunits. Biochemical and biophysical research communications $264 \quad 295: 849-853.1$

265 24. van de Locht, M., S. Donkervoort, J. M. de Winter, S. Conijn, L. Begthel, B. Kusters, P. Mohassel, Y. Hu, L. Medne,

${ }_{266}$ C. Quinn, S. A. Moore, R. Foley, G. Seo, D. T. Hwee, F. I. Malik, T. Irving, W. Ma, H. Granzier, E.-J. Kamsteeg,

${ }_{267}$ K. Immadisetty, P. Kekenes-Huskey, J. R. Pinto, N. Voermans, C. G. Bönnemann, and C. A. Ottenheijm, 2021.

${ }_{268}$ Pathogenic variants in TNNC2 cause congenital myopathy due to an impaired force response to calcium. The

269 Journal of Clinical Investigation . 1

270 25. Immadisetty, K., and J. D Madura, 2013. A review of monoamine transporter-ligand interactions. Current computer-aided drug design 9:556-568.

272 26. Immadisetty, K., and M. Moradi, 2020. Mechanistic Picture for Chemomechanical Coupling in a Bacterial

${ }_{273}$ Proton-Coupled Oligopeptide Transporter from Streptococcus Thermophilus. The Journal of Physical Chemistry B

275 27. Immadisetty, K., B. Sun, and P. M. Kekenes-Huskey, 2021. Structural Changes beyond the EF-Hand Contribute to Apparent Calcium Binding Affinities: Insights from Parvalbumins. The Journal of Physical Chemistry B 125:6390-6405.

278 28. Immadisetty, K., J. Hettige, and M. Moradi, 2019. Lipid-Dependent Alternating Access Mechanism of a Bacterial Multidrug ABC Exporter. ACS Central Science 5:43-56. 1

280 29. Acuña-Castillo, C., B. Morales, and J. P. Huidobro-Toro, 2000. Zinc and copper modulate differentially the P2X4

281 receptor. Journal of neurochemistry 74:1529-1537. 1 
282 30. Coddou, C., B. Morales, and J. P. Huidobro-Toro, 2003. Neuromodulator role of zinc and copper during prolonged

${ }_{283}$ ATP applications to P2X4 purinoceptors. European journal of pharmacology 472:49-56. 1

284 31. Coddou, C., C. Acuña-Castillo, P. Bull, and J. P. Huidobro-Toro, 2007. Dissecting the facilitator and inhibitor allosteric metal sites of the P2X4 receptor channel: critical roles of CYS132 for zinc potentiation and ASP138 for copper inhibition. Journal of Biological Chemistry 282:36879-36886. 1

287 32. Coddou, C., B. Morales, J. Gonzalez, M. Grauso, F. Gordillo, P. Bull, F. Rassendren, and J. P. Huidobro-Toro, 2003.

${ }_{288}$ Histidine 140 plays a key role in the inhibitory modulation of the P2X4 nucleotide receptor by copper but not zinc.

$289 \quad$ Journal of Biological Chemistry 278:36777-36785. 1

290 33. Coddou, C., R. A. Lorca, C. Acuña-Castillo, M. Grauso, F. Rassendren, and J. P. Huidobro-Toro, 2005. Heavy

291 metals modulate the activity of the purinergic P2X4 receptor. Toxicology and applied pharmacology 202:121-131.

$292 \quad 1$

293 34. Kasuya, G., Y. Fujiwara, M. Takemoto, N. Dohmae, Y. Nakada-Nakura, R. Ishitani, M. Hattori, and O. Nureki,

294 2016. Structural Insights into Divalent Cation Modulations of ATP-Gated P2X Receptor Channels. Cell Reports

$295 \quad 14: 932-944.1,2.1,2.4,4.1,7.1$

296 35. Li, M., Y. Wang, R. Banerjee, F. Marinelli, S. Silberberg, J. D. Faraldo-Gómez, M. Hattori, and K. J. Swartz, 2019.

297 Molecular mechanisms of human P2X3 receptor channel activation and modulation by divalent cation bound ATP.

$298 \quad$ eLife 8:e47060. 1, 2.1, 2.2, 2.4, 3, 4.1

299 36. Chataigneau, T., D. Lemoine, and T. Grutter, 2013. Exploring the ATP-binding site of P2X receptors. Frontiers in

300 cellular neuroscience 7:273. 1

301 37. Riedel, T., G. Schmalzing, and F. Markwardt, 2007. Influence of extracellular monovalent cations on pore and ${ }_{302}$ gating properties of P2X7 receptor-operated single-channel currents. Biophysical journal 93:846-858. 1

зоз 38. Du, J., H. Dong, and H.-X. Zhou, 2012. Gating mechanism of a P2X4 receptor developed from normal mode $304 \quad$ analysis and molecular dynamics simulations. Proceedings of the National Academy of Sciences 109:4140-4145. 1

305 39. Heymann, G., J. Dai, M. Li, S. D. Silberberg, H.-X. Zhou, and K. J. Swartz, 2013. Inter-and intrasubunit interactions

306 between transmembrane helices in the open state of P2X receptor channels. Proceedings of the National Academy

$307 \quad$ of Sciences 110:E4045-E4054.

${ }_{308}$ 40. Zhao, W.-S., J. Wang, X.-J. Ma, Y. Yang, Y. Liu, L.-D. Huang, Y.-Z. Fan, X.-Y. Cheng, H.-Z. Chen, R. Wang, et al., 2014. Relative motions between left flipper and dorsal fin domains favour P2X4 receptor activation. Nature communications 5:4189.

${ }_{311}$ 41. Turchenkov, D. A., and V. S. Bystrov, 2014. Conductance simulation of the purinergic P2X2, P2X4, and P2X7 ionic channels using a combined brownian dynamics and molecular dynamics approach. The Journal of Physical Chemistry B 118:9119-9127.

${ }_{314}$ 42. Huang, L.-D., Y.-Z. Fan, Y. Tian, Y. Yang, Y. Liu, J. Wang, W.-S. Zhao, W.-C. Zhou, X.-Y. Cheng, P. Cao, et al., 315 2014. Inherent dynamics of head domain correlates with ATP-recognition of P2X4 receptors: insights gained from $316 \quad$ molecular simulations. PloS one 9:e97528.

317 43. Pierdominici-Sottile, G., L. Moffatt, and J. Palma, 2016. The dynamic behavior of the P2X4 ion channel in the closed conformation. Biophysical journal 111:2642-2650.

${ }_{319}$ 44. Zhao, W. S., M. Y. Sun, L. F. Sun, Y. Liu, Y. Yang, L. D. Huang, Y. Z. Fan, X. Y. Cheng, P. Cao, Y. M. Hu, L. Li,

з20 Y. Tian, R. Wang, and Y. Yu, 2016. A highly conserved salt bridge stabilizes the kinked conformation of $\beta 2,3$-sheet

321 essential for channel function of P2X4 receptors. Journal of Biological Chemistry 291:7990-8003.

322 45. Wang, J., L. F. Sun, W. W. Cui, W. S. Zhao, X. F. Ma, B. Li, Y. Liu, Y. Yang, Y. M. Hu, L. D. Huang, X. Y. Cheng, ${ }_{323}$ L. Li, X. Y. Lu, Y. Tian, and Y. Yu, 2017. Intersubunit physical couplings fostered by the left flipper domain 324 facilitate channel opening of P2X4 receptors. Journal of Biological Chemistry 292:7619-7635. 1 
325 46. North, R. A., 2002. Molecular physiology of P2X receptors. Physiological reviews 82:1013-1067. 2.2

${ }_{326}$ 47. Cyphers, S., E. F. Ruff, J. M. Behr, J. D. Chodera, and N. M. Levinson, 2017. A water-mediated allosteric network

327 governs activation of Aurora kinase A. Nature chemical biology 13:402-408. 2.4

328 48. Gusic, M., K. Benndorf, and C. Sattler, 2021. Dissecting activation steps in P2X7 receptors. Biochemical and

329 Biophysical Research Communications 569:112-117. 3

${ }_{3}{ }^{2}$ 49. BERNSTEIN, F. C., T. F. KOETZLE, G. J. B. WILLIAMS, E. F. MEYER, M. D. BRICE, J. R. RODGERS,

${ }_{331}$ O. KENNARD, T. SHIMANOUCHI, and M. TASUMI, 1977. The Protein Data Bank. A Computer-Based Archival

332 File for Macromolecular Structures. European Journal of Biochemistry 80:319-324. 4.1

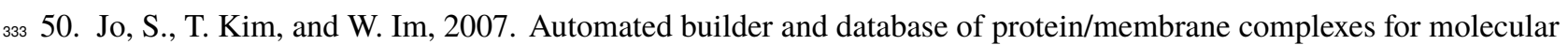

$334 \quad$ dynamics simulations. PLoS One 2:e880. 4.1

${ }_{335}$ 51. Lee, L. C., G. S. Kassab, and J. M. Guccione, 2016. Mathematical modeling of cardiac growth and remodeling.

${ }_{336} \quad$ Wiley Interdisciplinary Reviews: Systems Biology and Medicine 8:211-226. 4.1

${ }_{337}$ 52. Jorgensen, W. L., J. Chandrasekhar, J. D. Madura, R. W. Impey, and M. L. Klein, 1983. Comparison of Simple

338 Potential Functions for Simulating Liquid Water. Journal of Chemical Physics 79:926-935. 4.1

ззя 53. Case, D., T. Darden, T. E. Cheatham, C. Simmerling, J. Wang, R. E. Duke, R. Luo, R. C. Walker, W. Zhang, and

${ }_{340}$ K. M. Merz, 2012. Amber 12. University of California: San Francisco, CA . 4.1

${ }_{341}$ 54. Reid, J. K., 1971. On the Method of Conjugate Gradients for the Solution of Large Sparse Systems of Linear Equations. In J. K. Reid, editor, Large Sparse Sets of Linear Equations, Academic Press, London, 231-254. 4.1

${ }_{343}$ 55. Case, D., R. Betz, D. Cerutti, T. Cheatham, T. Darden, R. Duke, T. Giese, H. Gohlke, A. Götz, N. Homeyer, S. Izadi,

${ }_{344}$ P. Janowski, J. Kaus, A. Kovalenko, T.-S. Lee, S. LeGrand, P. Li, C. Lin, T. Luchko, and P. A. Kollman, 2016.

345 Amber 16. University of California: San Francisco, CA . 4.1

${ }_{346}$ 56. Martyna, G. J., D. J. Tobias, and M. L. Klein, 1994. Constant pressure molecular dynamics algorithms. Journal of

347 Chemical Physics 101:4177-4189. 4.1

${ }_{348}$ 57. Feller, S. E., Y. Zhang, R. W. Pastor, and B. R. Brooks, 1995. Constant pressure molecular dynamics simulation: The Langevin piston method. Journal of Chemical Physics 103:4613-4621. 4.1

350 58. Darden, T., D. York, and L. Pedersen, 1993. Particle mesh Ewald: An N . elog(N) method for Ewald sums in large $351 \quad$ systems. The Journal of chemical physics 98:10089-10092. 4.1

352 59. Ryckaert, J.-P., G. Ciccotti, and H. J. C. Berendsen, 1977. Numerical integration of the cartesian equations of motion

${ }_{353}$ of a system with constraints: molecular dynamics of n-alkanes. Journal of Computational Physics 23:327-341. 4.1

${ }_{354}$ 60. Humphrey, W., A. Dalke, and K. Schulten, 1996. VMD: visual molecular dynamics. Journal of Molecular Graphics $355 \quad 14: 33-38.4 .1$

${ }_{356}$ 61. Roe, D. R., and T. E. Cheatham, 2013. PTRAJ and CPPTRAJ: Software for processing and analysis of molecular

${ }_{357}$ dynamics trajectory data. Journal of Chemical Theory and Computation 9:3084-3095. 4.1, S7

${ }_{358}$ 62. Towns, J., T. Cockerill, M. Dahan, I. Foster, K. Gaither, A. Grimshaw, V. Hazlewood, S. Lathrop, D. Lifka,

${ }_{359}$ G. D. Peterson, R. Roskies, J. R. Scott, and N. Wilkens-Diehr, 2014. XSEDE: Accelerating Scientific Discovery. 


\section{${ }_{361} 7$ SUPPLEMENTARY MATERIAL}

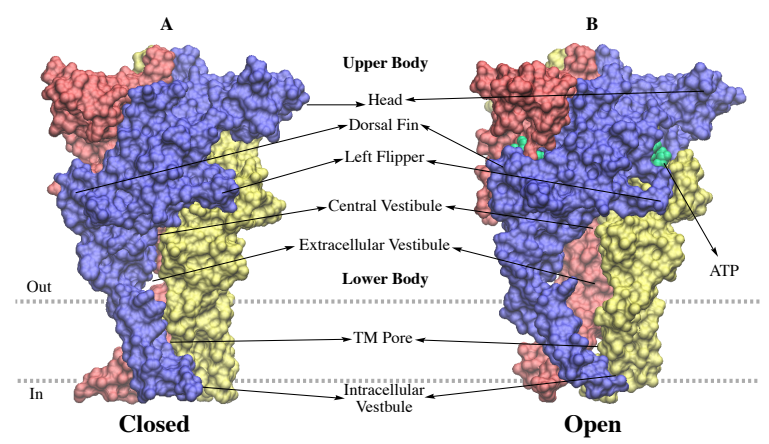

Figure S1: Closed (A) and open state (B) crystal structures of zfP2X4. The three isomers are colored blue, red, and yellow, respectively. The closed structure is in apo form and ATP is binding in the open state structure between the isomers. ATP is shown in green. The TM pore, which is formed by the TM domain of each isomer, is the narrowest part of the channel. The TM pore is closed when deactivated and open when activated.

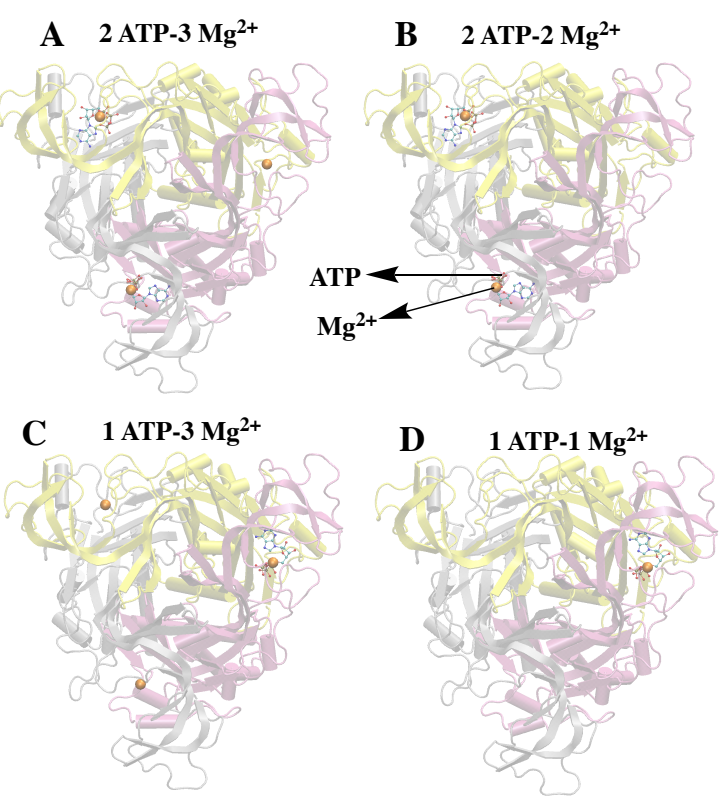

Figure S2: The remaining four $\mathrm{p} 2 \times 4$ structures were studied with $\mathrm{Mg}^{2+}$ docked in MBS2. Top views of all four structures are shown. (A) 2 ATP-3 $\mathrm{Mg}^{2+}$ structure has two ATP and three $\mathrm{Mg}^{2+}$ ions, (B) 2 ATP- $2 \mathrm{Mg}^{2+}$ structure has two ATP and two $\mathrm{Mg}^{2+}$ ions, (C) 1 ATP- $3 \mathrm{Mg}^{2+}$ structure has one ATP and three $\mathrm{Mg}^{2+}$ ions, and (D) 1 ATP- $1 \mathrm{Mg}^{2+}$ structure has one ATP and one $\mathrm{Mg}^{2+}$ ions. $\mathrm{Mg}^{2+}$ is shown as orange spheres and ATP is represented as a ball-and-stick model.

\section{7.1 MBS1 binding}

${ }_{363}$ The number of $\mathrm{K}^{+}$binding in MBS1 was estimated. On average, two to three $\mathrm{K}^{+}$ions were consistently present in ${ }_{364} \mathrm{MBS1}$ in the 3-ATP and 2-ATP systems, whereas in the 1-ATP system they were reduced from three to one in the course ${ }_{365}$ of the simulation (Fig. 3E). We hypothesize that this is due to the collapse of the channel in the 1-ATP system, thus ${ }_{366}$ collapsing MBS1. Studies have reported that zinc $\left(\mathrm{Zn}^{2+}\right)$ binding to MBS1 potentiates ATP-mediated currents in the ${ }_{367}$ Gulf coast P2X channel through allostery (34). To some extent, we have observed $\mathrm{K}^{+}$binding MBS1 playing a similar ${ }_{368}$ role as $\mathrm{Zn}^{2+}$. For instance, a greater number of $\mathrm{K}^{+}$ions are binding in this site when two or more ATP are binding ${ }_{369}$ in the MBS2. This indicates that $\mathrm{K}^{+}$and $\mathrm{Zn}^{2+}$ are working in correlation and that $\mathrm{K}^{+}$help stabilizes the open state ${ }_{370}$ structure in the presence of ATP, which is needed to facilitate greater ion/current flow. Additionally, we have identified ${ }_{371}$ that $\mathrm{K}^{+}$ions were occupying the MBS2 and interacting with the ATP (Fig. 3A). Furthermore, we estimated that at least ${ }_{372}$ one $\mathrm{K}^{+}$ion was bound in the MBS2 (Fig. 3F-H). Additionally, we identified a correlation between ATP binding to the ${ }_{373}$ channel and $\mathrm{K}^{+}$ions binding to the MBS2, i.e., when no ATP binds to an ATP binding site, no $\mathrm{K}^{+}$ions were binding to ${ }_{374}$ the respective MBS2, and vice versa. For instance, in the 3-ATP system, three ATP molecules bind to the three ATP ${ }_{375}$ binding sites and subsequently, we observed $\mathrm{K}^{+}$ions binding to all three MBS2s. However, with the 2-ATP system $\mathrm{K}^{+}$ 376 ions were bound near the two ATP binding sites that were occupied by ATP but not near the ATP binding site that was 


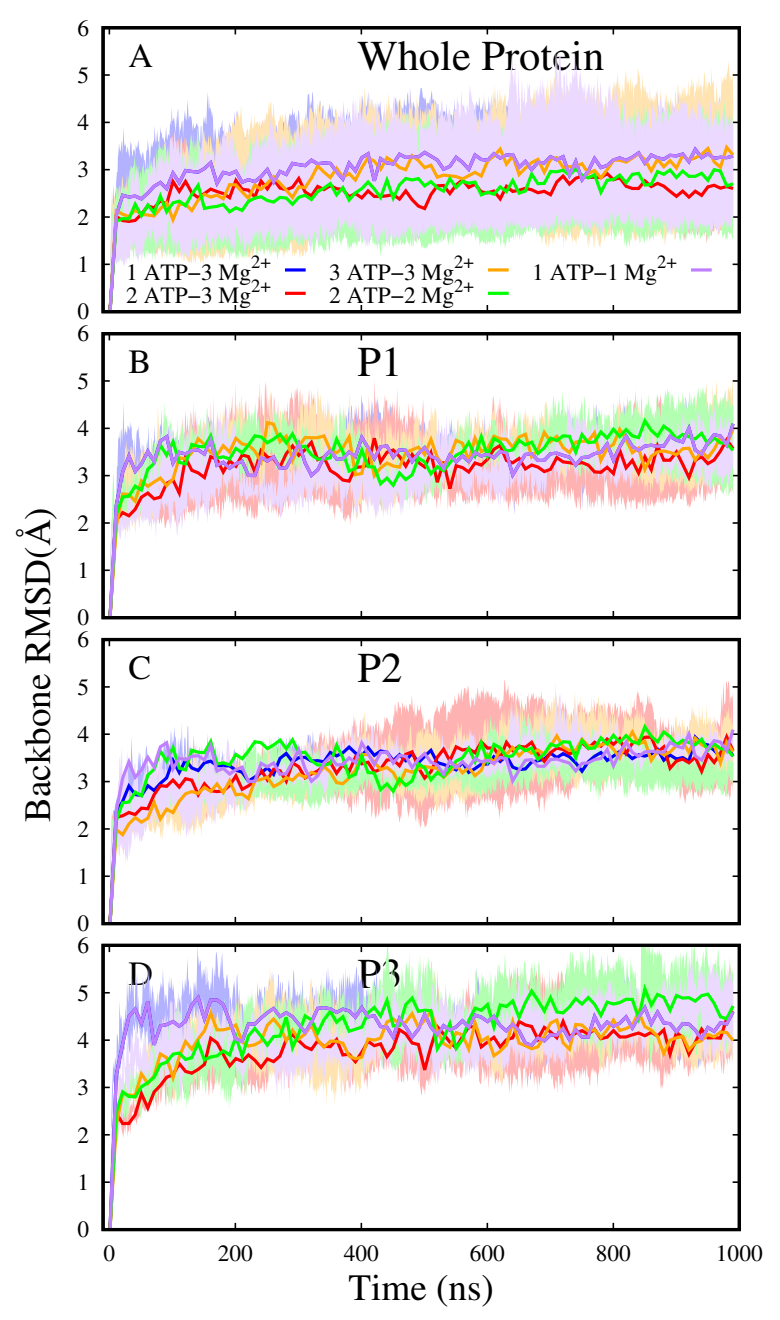

Figure S3: Backbone RMSD vs. Time for $\mathrm{Mg}^{2+}$ bound systems. RMSD of the whole protein is shown in $\mathrm{A}$ and of the three isomers in panels B-D. The average and standard deviation of all three MD are shown.
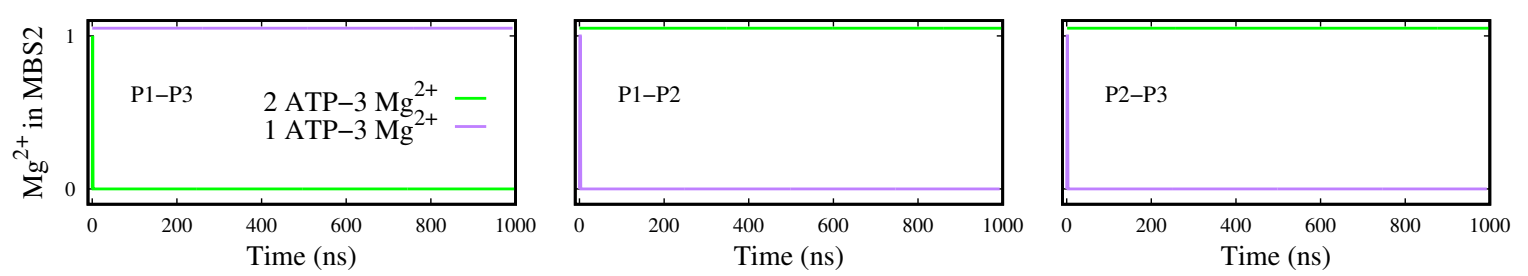

Figure S4: $\mathrm{Mg}^{2+}$ in MBS2 sites of $2 \mathrm{ATP}-3 \mathrm{Mg}^{2+}$ and $1 \mathrm{ATP}-3 \mathrm{Mg}^{2+}$ systems. The three columns represent $\mathrm{Mg}^{2+}$ in the three MBS2 sites in the channel. $\mathrm{Mg}^{2+}$ left the MBS2 sites in the absence of ATP in 1 ATP- $3 \mathrm{Mg}^{2+}$ and 2 ATP- $3 \mathrm{Mg}^{2+}$ systems. 


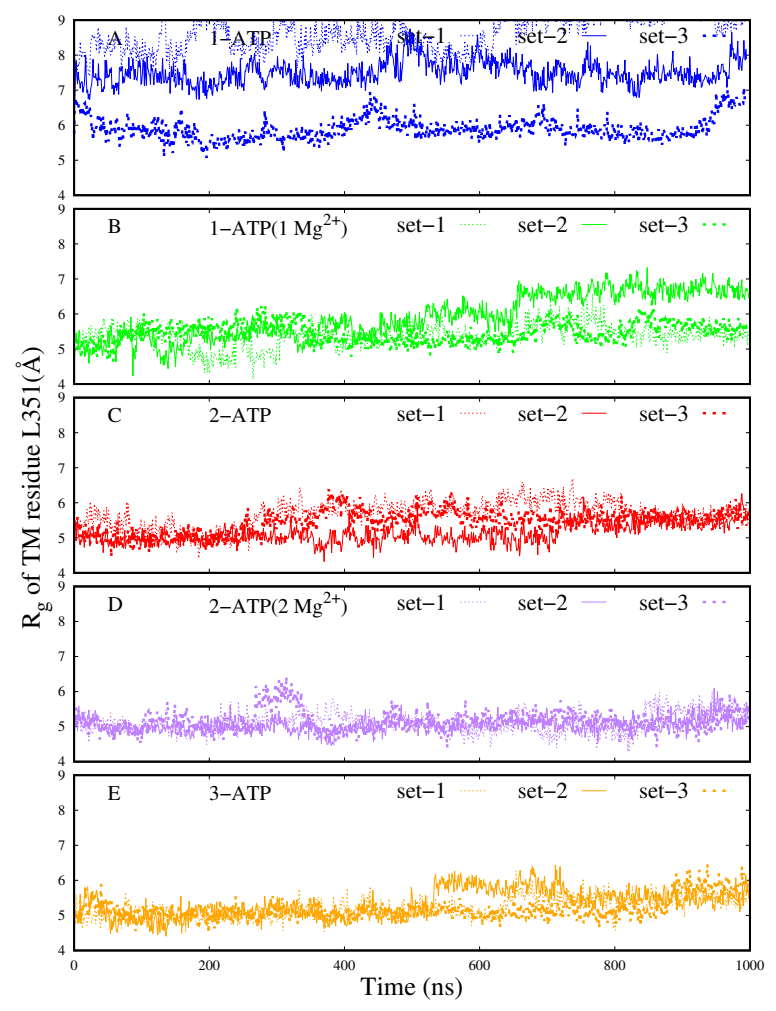

Figure S5: Radius of gyration vs. Time for $\mathrm{Mg}^{2+}$ bound systems. All three MD trials of each system are shown separately.

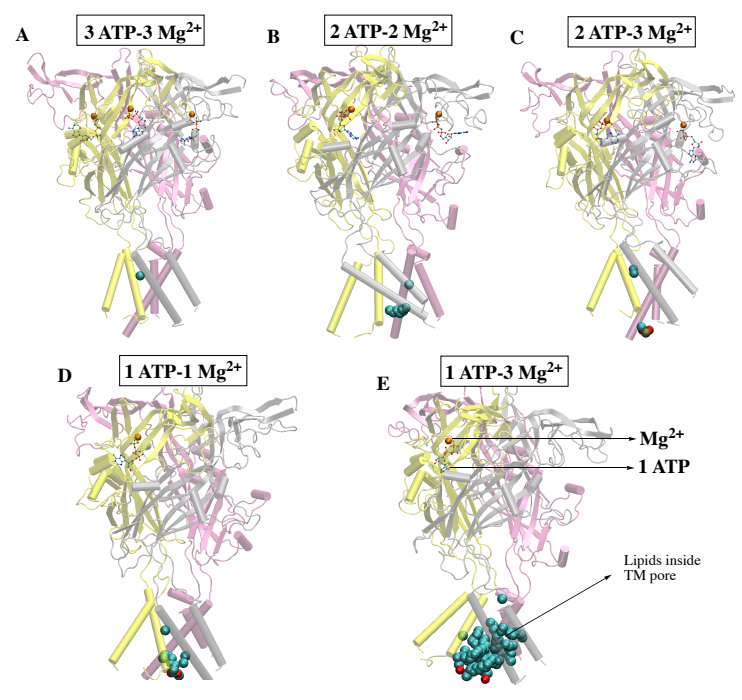

Figure S6: Representative MD snapshots of all five $\mathrm{Mg}^{2+}$ bound P2X4 systems. Lipids inside the TM pore are shown. 

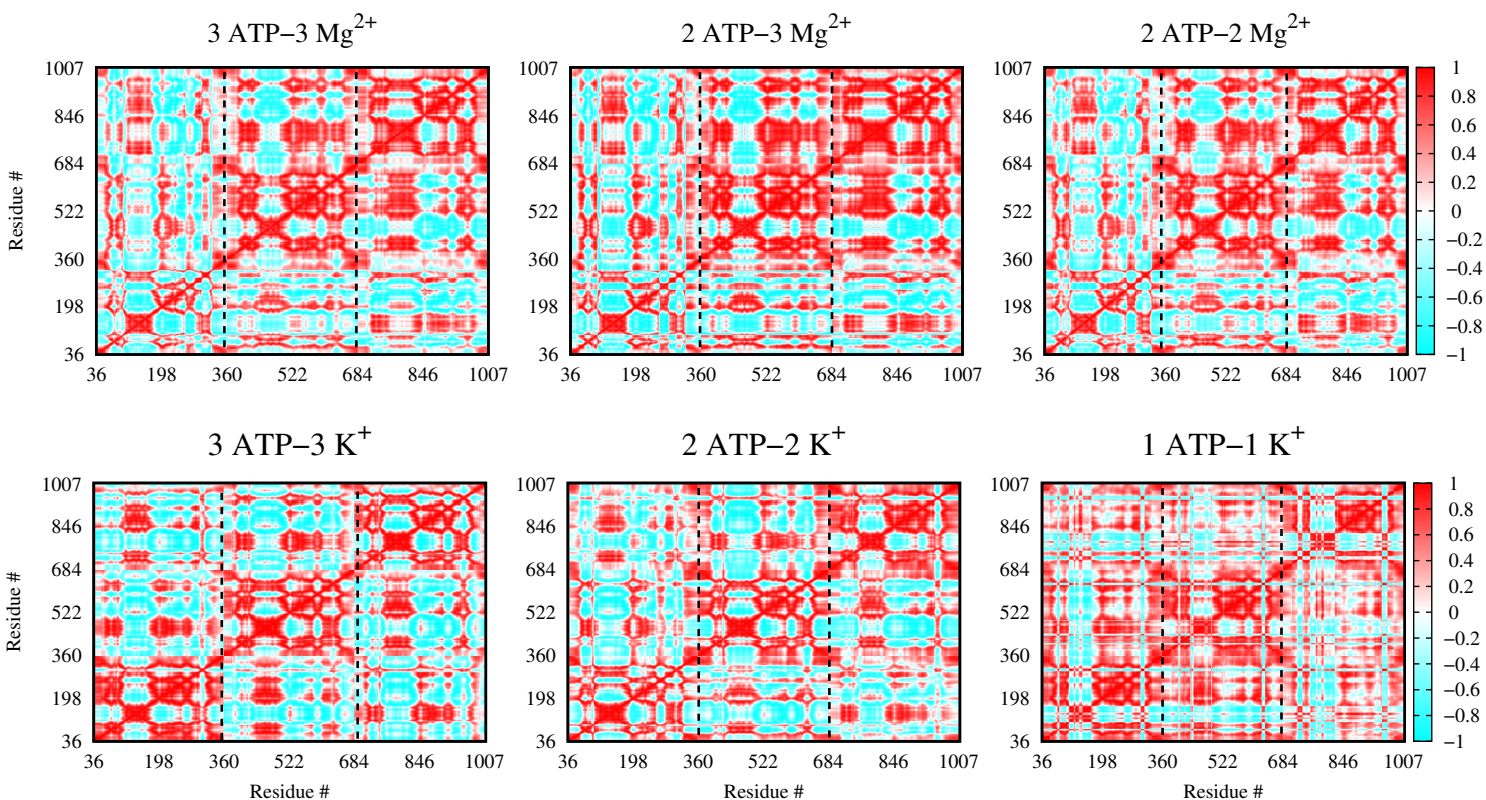

Figure S7: Dynamic cross-correlation heat maps of $\mathrm{Mg}^{2+}$ and $\mathrm{K}^{+}$bound systems. All three MD trials of each system were combined for this analysis; only $\mathrm{C}_{\alpha}$ atoms were considered. The color bar on the right represents the extent of cross-correlation; -1, 0 , and 1 represent negative correlation (cyan), no correlation (white), and positive correlation (red), respectively. Cpptraj (61) of the amber package was used for this analysis.
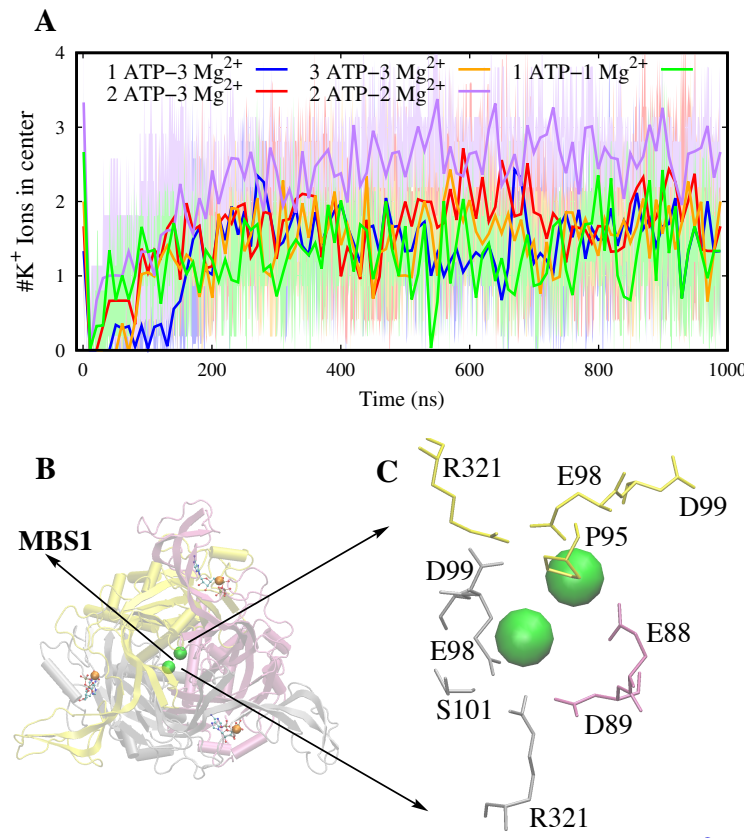

Figure S8: $\mathrm{K}^{+}$ions in MBS1 in $\mathrm{Mg}^{2+}$ bound systems. The \# of $\mathrm{K}^{+}$found in the MBS1 site as a function of simulation time is shown. Average and standard deviation of three MD trials are shown. (B) MD snapshot of the $3 \mathrm{ATP}-3 \mathrm{Mg}^{2+}$ system with $\mathrm{K}^{+}$binding to MBS1 is shown. (C) Close-up of MBS1 and residues within $5 \AA$ of $\mathrm{K}^{+}$are shown. Residues are colored according to the isomer they belong to. $\mathrm{K}^{+}$ions are shown as green-colored spheres.

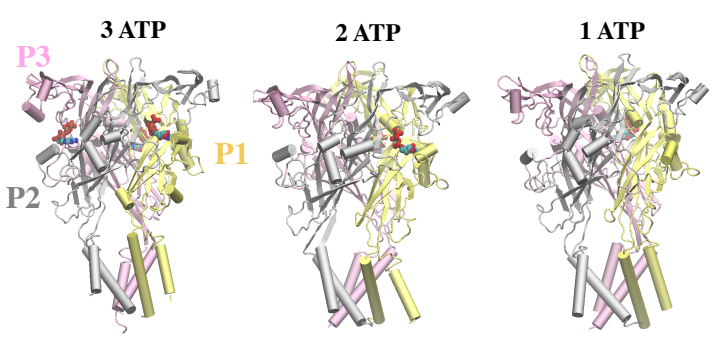

Figure S9: The three zfP2X4 structures studied. P1, P2, and P3 domains are colored yellow, grey, and magenta, respectively. ATP molecules are shown as ball-and-stick representations. 1-ATP: ATP binds between P1 and P3 domains; 2-ATP: ATP binds between P1, P2, and P1, P3 domains. Side views of all three structures are shown. 


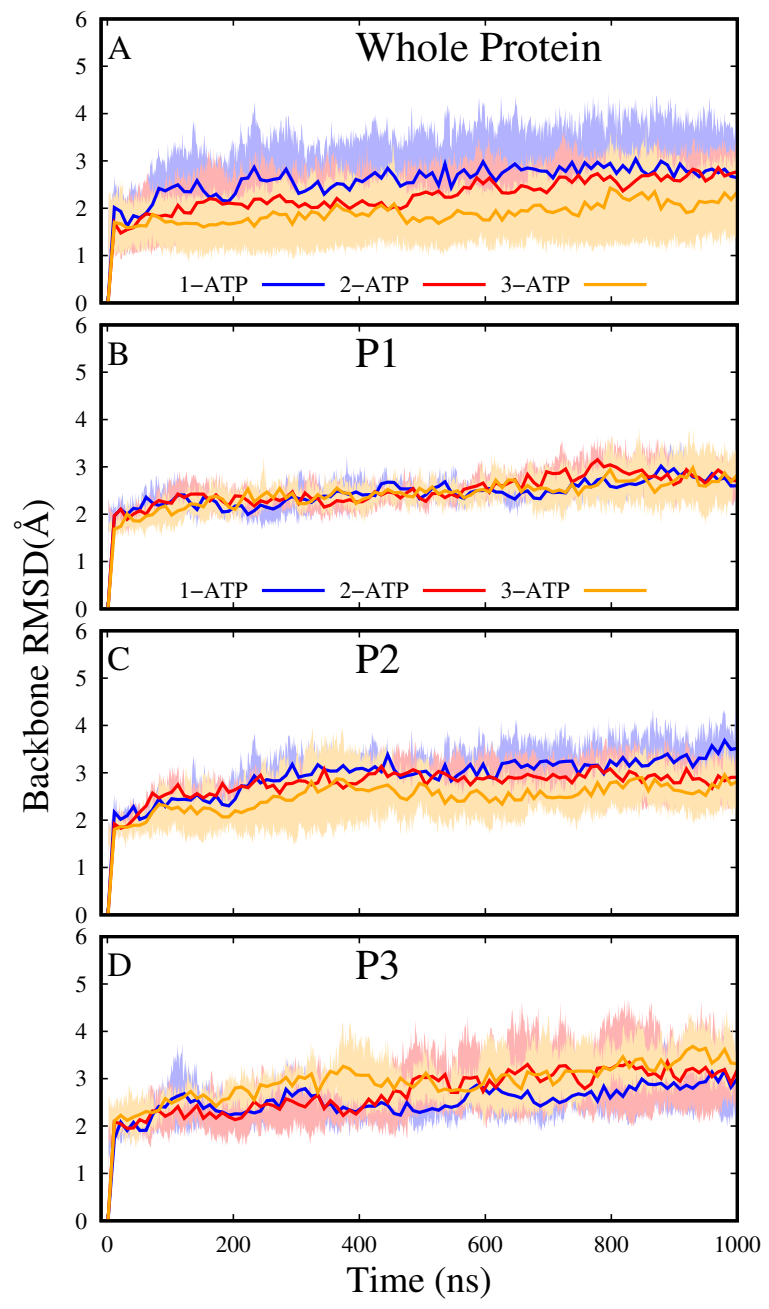

Figure S10: Backbone RMSD vs. Time. A RMSD of whole protein. B-D RMSDs of the three isomers. The average of three MD trials of each system is shown and the error bars (i.e., standard deviation) are shaded.

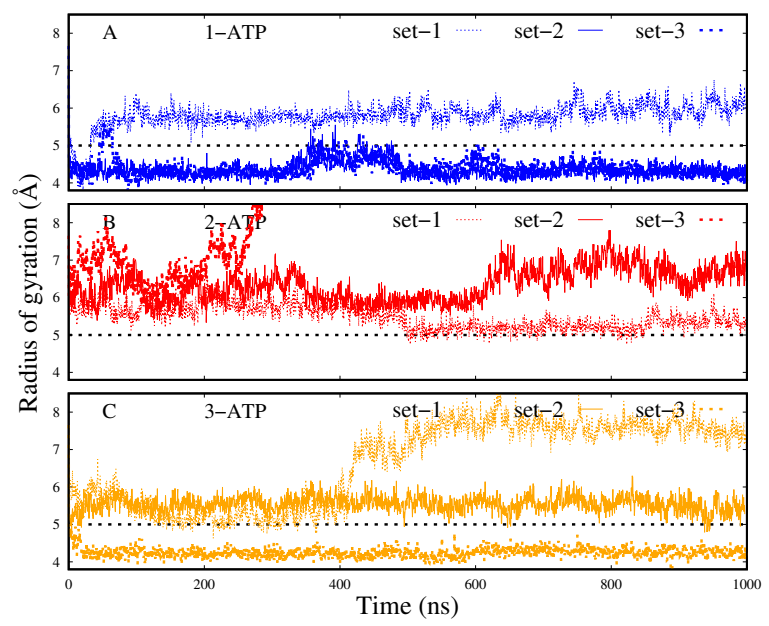

Figure S11: $\mathrm{R}_{g}$ vs. time of residue L351. 1-, 2-, and 3-ATP systems are colored blue, red, and orange, respectively. The dotted horizontal line at $\mathrm{Y}=5$ separates 1-ATP system from the other two systems. $\mathrm{R}_{g}$ of 1-ATP systems were less than 5 $\AA$, except for one outlier (set-1). On the other hand, the $\mathrm{R}_{g}$ of 2 - \& 3-ATP systems are greater than $5 \AA$, except for one outlier in the 3-ATP system (set-3). 


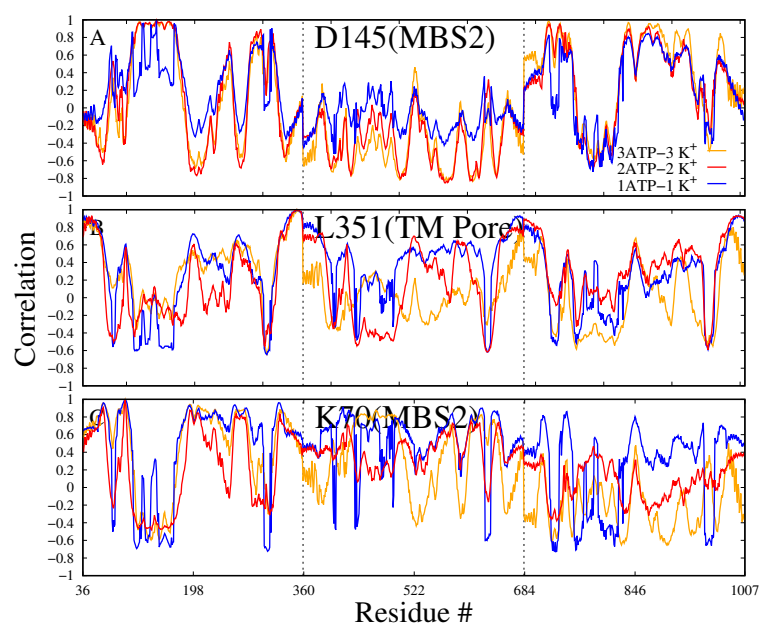

Figure S12: Correlation plots of select few residues of interest of $\mathrm{K}^{+}$bound systems. The dotted lines separate the three monomers. $-1,0$, and 1 on the y-axis refers to anti-correlation, no correlation, and positive correlation, respectively.

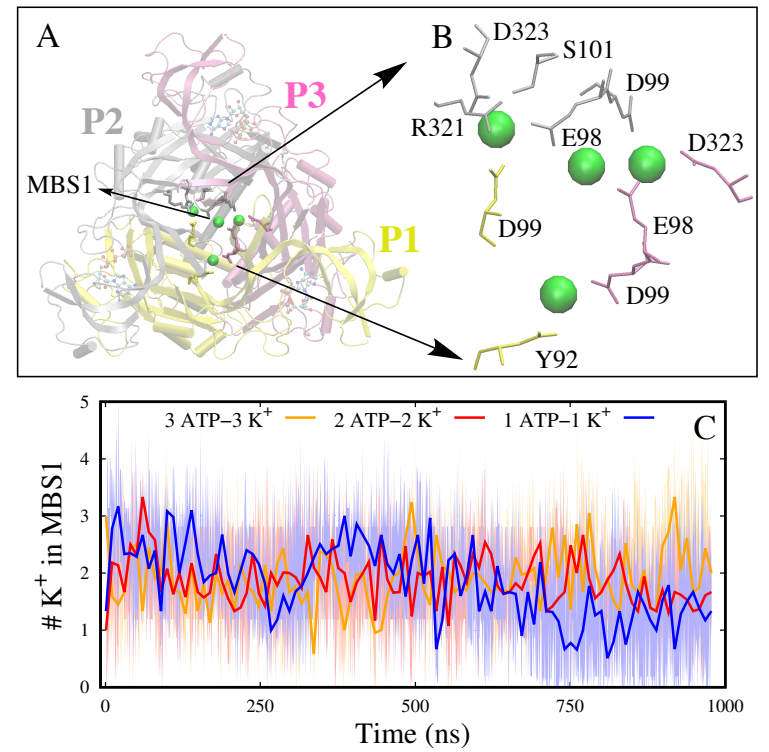

Figure S13: $\mathrm{K}^{+}$ions binding in MBS1 coordinating the three isomers inside the vestibule. A Top view is shown. B MBS1 close-up view. C Average number of $\mathrm{K}^{+}$ions binding in MBS1. Ions within $8 \AA$ of all three isomers inside the vestibule are considered for these calculations. 
377 not occupied by ATP (i.e., the site between domains P2 and P3) (Fig. 3 F-H). Similarly, in the 1-ATP system, $\mathrm{K}^{+}$was ${ }_{378}$ binding in the MBS2 adjacent to the site occupied by ATP (i.e., between the domains P1 and P3) and absent in the other ${ }_{379}$ two MBS2 sites. This is similar to what we have observed in the $\mathrm{Mg}^{2+}$ bound simulations.

${ }_{380}$ We have observed $\mathrm{K}^{+}$ions occupying the MBS1 in all five $\mathrm{Mg}^{2+}$ bound systems studied (Fig. S8) and coordinating ${ }_{381}$ the three isomers via interacting with the polar (such as S101 and Y99) and negatively charged (such as E98, D99, and ${ }_{382}$ D323) residues of the protein (Fig. S8B, C). Irrespective of the number of ATP binding to the channel, on average 2-3 ${ }_{383} \mathrm{~K}^{+}$were binding to the MBS1 (Fig. S8A). This is a highly conserved site across the P2X4 receptors and residues that 384 are interacting with the $\mathrm{zfP} 2 \mathrm{X} 4$ are similar to other $\mathrm{P} 2 \mathrm{X}$ receptors (34).

${ }_{385} \mathrm{~K}^{+}$ions were also identified in MBS1 in the three $\mathrm{K}^{+}$bound systems simulated (Fig. S13).

\section{${ }_{386}$ ACRONYMS}

${ }_{387} \mathbf{C a}^{2+}$ calcium. 2

${ }_{388} \mathrm{Cl}^{-}$chloride. 7

${ }_{389} \mathbf{K}^{+}$potassium. $1-7,12,15,17,18$

${ }_{390}$ MBS2 metal binding site 2. 3

391 MD molecular dynamics. 1, 2, 4, 6, 7, 13-16

${ }_{392} \mathbf{M g}^{2+}$ magnesium. 1-7, 12-15, 18

${ }_{393} \mathbf{N a}^{+}$sodium. 2, 4

${ }_{394} \mathbf{R}_{g}$ radius of gyration. 3, 4, 16

395 RMSD root mean squared deviations. 3, 13

${ }_{396}$ TMD transmembrane domain. 2

${ }_{397}$ zfP2X4 zebrafish P2X4. 2-4, 7, 12, 15, 18

${ }_{398} \mathbf{Z n}^{2+}$ zinc. 12 